\title{
One-step Integrated Surface Modification to Build a Stable Interface on High-voltage Cathode for Lithium-ion Batteries
}

\author{
Rui Zhao $,{ }^{\dagger} \mathrm{Li} \mathrm{Li},{ }^{\dagger}$ Tinghua Xu,${ }^{\dagger}$ Dandan Wang,${ }^{\dagger}$ Du Pan,${ }^{\dagger}$ Guanjie He,${ }^{\ddagger}$ Huiling Zhao ${ }^{+, *}$ \\ and Ying Bai ${ }^{+, *}$ \\ ${ }^{+}$Key Laboratory of Photovoltaic Materials of Henan Province and School of Physics \& Electronics, \\ Henan University, Kaifeng 475004, P.R China \\ ${ }^{\ddagger}$ Materials Research Centre, UCL Department of Chemistry, Christopher Ingold Building, 20 \\ Gordon Street, London, WC1H OAJ, UK. \\ *Corresponding author. Tel.: +86-0371-23881602; 13781181979 \\ E-mail address: ybai@henu.edu.cn; zhao@henu.edu.cn
}

Supplementary material: Figure S1-S10, Table S1-S4.

Abstract: As one of the most promising cathode materials for next generation energy storage applications, spinel $\mathrm{LiNi}_{0.5} \mathrm{Mn}_{1.5} \mathrm{O}_{4}$ (LNMO) has been highlighted due to many advantages. However, it is still hindered by poor electrochemical stability derived from the bulk/interface structure degradation and side-reactions under high working voltage. In this work, fast ion conductor $\mathrm{Li}_{3} \mathrm{~V}_{2}\left(\mathrm{PO}_{4}\right)_{3}$ (LVPO) is adopted to modify the surface of spinel LNMO by a one-step facile method to harvest the maximum benefit of interface properties. It is found that 1 wt.\% LVPO-LNMO exhibits the most excellent cycling performances, retaining a great capacity retention of $87.8 \%$ after 500 cycles at room 
temperature and $82.4 \%$ for 150 cycles at $55{ }^{\circ} \mathrm{C}$. Moreover, the rate performance is also significantly improved (90.4 $\mathrm{mAh} \mathrm{g}^{-1}$ under $\left.20 \mathrm{C}\right)$. It is revealed that the LVPO-involved layer could effectively suppress the surface side-reactions under high working voltage, which mainly contribute an improved interface with desirable structure stability and excellent kinetics behaviour without sacrificing the surface electrochemical activity in electrochemical environment. Thus, the dissolution of transition metal ions is effectively mitigated with avoiding further structure degradation of bulk material. Especially, it is also established that the vanadium $(\mathrm{V})$ ions in $\mathrm{LVPO}$ could be to a certain extent migrated into the surface lattice of LNMO to generate a V-involved transition layer (Li-Ni-Mn-V-O surface solid solution), which greatly co-contributes to the enhanced electrochemical performances owning to the prominently depressed charge transfer resistance.

Keywords: Lithium-ion batteries; $\mathrm{LiNi}_{0.5} \mathrm{Mn}_{1.5} \mathrm{O}_{4}$; Fast ion conductors; Integrated surface modification.

\section{Introduction}

As one of the most successfully commercialized energy storage technologies in portable devices, $\mathrm{Li}$-ion batteries (LIBs) are highly regarded as the key components for electric vehicles (EVs) and hybrid EVs (HEVs) due to their high energy density, long cycling life, and environment friendliness. ${ }^{1-3}$ In this regard, a vast of theoretical explorations and technological innovations have been endeavoured to 
pursuing more novel cathode materials in the viewpoint of richer resources, higher energy densities and more stable electrochemical performances to substitute for the currently applied $\mathrm{LiCoO}_{2}, \mathrm{LiMn}_{2} \mathrm{O}_{4}$, and $\mathrm{LiFePO}_{4}$ etc. Among the cathode candidates, spinel $\mathrm{LiNi}_{0.5} \mathrm{Mn}_{1.5} \mathrm{O}_{4}$ (LNMO) has been considered as one of the most attractive materials for next generation high energy density LIBs, on account of its high operating voltage $\left(\sim 4.7 \mathrm{~V} v s . \mathrm{Li} / \mathrm{Li}^{+}\right)$, high energy density $\left(\sim 650 \mathrm{Wh} \mathrm{kg}^{-1}\right)$, cost effective and excellent rate capability owing to the three-dimensional diffusion channel. ${ }^{4-9}$ Nevertheless, severe side reactions under high work potential and the resultant increased cell impedance, deteriorated $\mathrm{Li}^{+}$diffusion kinetics and fast degradation in interface stabilities as well as electrochemical capabilities greatly hinder its practical application, especially at elevated temperatures. ${ }^{10-12} \mathrm{On}$ the other hand, the inevitable dissolution of transition metal ions (Mn, Ni) into electrolyte during electrochemical process also partly accounts for its obvious capacity degradation and poor coulombic efficiency. ${ }^{13}$ Therefore, it is of great significance to ameliorate the interface property between LNMO active material and electrolyte.

To this end, various modification materials such as metal oxides, fluorides and phosphates, including $\mathrm{Al}_{2} \mathrm{O}_{3}, \mathrm{LaF}_{3}, \mathrm{AlF}_{3}, \mathrm{FePO}_{4}, \mathrm{YPO}_{4}, \mathrm{LiAlO}_{2}, \mathrm{Li}_{4} \mathrm{Ti}_{5} \mathrm{O}_{12}$ $\mathrm{Li}_{2} \mathrm{SiO}_{3}, \mathrm{Li}_{2} \mathrm{SnO}_{3}$ etc., have been extensively applied to modify the spinel LNMO. ${ }^{12,14-23}$ It is generally found that the proposed protective layers on the 
surface could effectively prevent the direct contact of LNMO with electrolyte, thus suppresses the oxidation of electrolyte and the consistent growth of cathode-electrolyte interface (CEI) layer, mitigates the dissolution of TM ions and enhances the $\mathrm{Li}^{+}$diffusion dynamics during electrochemical cycling. Besides, surface modification was also reported to suppress surface structure transformation and improve thermal properties. ${ }^{24}$ However, despite all the previous efforts and progress, high voltage LNMO cathode material has not been successfully commercialized yet due to the unsatisfactory interface and electrochemical properties, which are more pronounced at elevated temperatures, suggesting that a complete understanding and tactful construction of a desirable interface is of great significance for further performance improvement of LNMO ${ }^{25}$ As an alternative strategy to decorate the spinel LNMO, it has been revealed that element doping, such as $\mathrm{P}^{5+}, \mathrm{Nb}^{5+}, \mathrm{Ti}^{4+}, \mathrm{Al}^{3+}, \mathrm{Cr}^{3+}, \mathrm{Si}^{4+}$ and $\mathrm{Zr}^{4+}$, could also effectively enhance the LNMO property in both rate capability and cyclic performance through minimizing polarization, retarding the $\mathrm{TM}$ dissolution and improving the ionic/electronic conductivities. ${ }^{4,26-30} \mathrm{Kim}$ et al. found that vanadium $\left(\mathrm{V}^{5+}\right)$ in the $\mathrm{Li}$ sites of spinel LNMO could prevent Mn dissolution and diminish possible by-product, resulting in increased conductivity and electrochemical activity. ${ }^{31}$ Besides the traditional bulk doping route, novel surface pinning strategies with similar enhancement effect have also been proposed very recently. Wang et al. showed that a gradient entrance of a small amount of $\mathrm{Ti}$ ions promoted the 
electrochemical performances of LNMO through reconstructing the surface/subsurface lattices and impeding the migration/dissolution of TM ions, without influencing the interior crystal structure. ${ }^{32}$ To build a steady interface, Piao et al. introduced an epitaxial surface layer of $\mathrm{AlPO}_{4}$ outside $\mathrm{LNMO}$, followed by an $\mathrm{Al}^{3+}$ diffusion process, in order to suppress the structural degradation during cycling by increasing the surface stability. ${ }^{33}$ Besides, Chen et al. established an ultrathin $\quad \mathrm{LiAlO}_{2}$-inlaid $\quad \mathrm{LiNi}_{0.5} \mathrm{Co}_{0.2} \mathrm{Mn}_{0.3} \mathrm{O}_{2} \quad$ composites via a hydrolysis-hydrothermal approach, with coated by crytalline $\mathrm{LiAlO}_{2}$ and doped by partial $\mathrm{Al}^{3+}$ to obtain exhibit excellent reversible capacity, enhanced cyclability and rate properties. ${ }^{34}$ Moreover, Yan et al. realized remarkable enhancement in structural and interfacial stabilities of Ni-rich $\mathrm{LiNi}_{0.76} \mathrm{Mn}_{0.14} \mathrm{Co}_{0.10} \mathrm{O}_{2}$ by a novel coating and subsequent infusion route, leading to a long-term cycling stability in both capacity and voltage. ${ }^{35}$ The above findings indicate that, surface lattice pinning, as a supplement approach for traditional surface coating/bulk doping, has a great chance to be utilized to build a desirable interface for cathode materials. In this regard, with the strategy of $\mathrm{Li}_{2} \mathrm{SnO}_{3}$ surface coating and $\mathrm{F}$ surface pinning, the electrochemical performances of Li-rich cathode material were significantly enhanced by our group. ${ }^{36}$ Nevertheless, the two-step strategy plunged the modification in complicated and unrepeatable procedure, which was massively more likely to degrade the lattice structure of active material. ${ }^{37}$ Therefore, Lu et al. have theoretically predicted and successfully synthesized a Ti-doped and 
$\mathrm{La}_{4} \mathrm{NiLiO}_{8}$-coated $\mathrm{LiNi}_{0.8} \mathrm{Co}_{0.1} \mathrm{Mn}_{0.1} \mathrm{O}_{2}$ composite cathode via a simple one-step calcination approach, which is the significant enhancement of electrochemical performance in terms of rate capability and cycling stability. ${ }^{38}$

Very recently, many researches have been carried out to explore the application of fast ion conductors including $\mathrm{Li}_{10} \mathrm{GeP}_{2} \mathrm{~S}_{12}, \mathrm{Li}_{7} \mathrm{La}_{3} \mathrm{Zr}_{2} \mathrm{O}_{12}$, $\mathrm{Li}_{1.3} \mathrm{Al}_{0.3} \mathrm{Ti}_{1.7}\left(\mathrm{PO}_{4}\right)_{3}, \mathrm{Li}_{0.33} \mathrm{La}_{0.56} \mathrm{TiO}_{3}$ and $\mathrm{Li}_{3} \mathrm{~V}_{2}\left(\mathrm{PO}_{4}\right)_{3}(\mathrm{LVPO})$ as solid electrolytes or cathode materials for LIBs. ${ }^{39-44}$ Among them, monocline LVPO has attracted great interest for its many advantages including high energy density, high operating voltage (up to $\sim 4.6 \mathrm{~V}$ ), good $\mathrm{Li}^{+}$diffusion coefficient $\left(10^{-10} \sim 10^{-8} \mathrm{~cm}^{2}\right.$ $\mathrm{s}^{-1}$ ), excellent thermal and structural stabilities. ${ }^{45}$ As inspired by Kim et al., the accompanied $\mathrm{V}$ doping of LVPO coating has a great chance to strengthen the modification effect in LVPO coating process. ${ }^{31}$

In this work, a one-step sol-gel route was employed to successfully modify the surface of LNMO with a homogeneous thin layer of LVPO (Scheme 1). The integrated modification of LVPO, as expected, greatly improved the electrochemical properties of LNMO material. Chemical and electrochemical aging tests revealed that the CEI film generation and the surface structure degradation could be effectively remitted. As a feature of this work, the V ions in LVPO were found gradiently migrated into the surface lattice of LNMO, generating a V-involved Li-Ni-Mn-V-O surface solid solution and facilitating the 
surface kinetics behavior (effectively suppressed the $\mathrm{R}_{\mathrm{ct}}$ ). The multi-functions of LVPO modification layer revealed herein not only paved the way to commercial application of spinel LNMO, but also shed light in the integrated modification and surface functionalization of electrode materials in various energy storage devices.

\section{Experimental section}

\subsection{Material synthesis}

Bare LNMO was synthesized by a conventional sol-gel method. Stoichiometric amounts of $\mathrm{CH}_{3} \mathrm{COOLi}$ (Aladdin, $99 \%$ ), $\left(\mathrm{CH}_{3} \mathrm{COO}\right)_{2} \mathrm{Ni} \cdot 4 \mathrm{H}_{2} \mathrm{O}$ (Aladdin, 99\%) and $\left(\mathrm{CH}_{3} \mathrm{COO}\right)_{2} \mathrm{Mn} \cdot 4 \mathrm{H}_{2} \mathrm{O}$ (Aladdin, $99 \%$ ) precursors were dissolved in ultrapure water and thoroughly blended with citric acid, wherein the mole ratio between total transition metal ions and citric acid was fixed at 1:1.5. Then, the PH value of the above solution was adjusted to 6.5 by slowly adding ammonium hydroxide. With fierce stirring, the green mixed solution was gradually evaporated at $80^{\circ} \mathrm{C}$ until the viscous gel was formed and subsequently dried at $120{ }^{\circ} \mathrm{C}$ for $24 \mathrm{~h}$ to form a dry gel. Finally, the gel was collected and preheated at $500{ }^{\circ} \mathrm{C}$ for $6 \mathrm{~h}$ to eliminate the organic components, followed by carefully grinding and annealing at $820^{\circ} \mathrm{C}$ for 14 $\mathrm{h}$ in air (with the heating and the cooling rates of 1 and $5{ }^{\circ} \mathrm{C} \mathrm{min}^{-1}$, respectively).

To prepare LVPO-modified $\left(0.5,1\right.$ and 2 wt.\%) LNMO samples, $\mathrm{V}_{2} \mathrm{O}_{5}$ (Chemical Reagent, 99\%), $\mathrm{NH}_{4} \mathrm{H}_{2} \mathrm{PO}_{4}$ (Kermel, 99\%), $\mathrm{Li}_{2} \mathrm{CO}_{3}$ (Kermel,97\%) and 
citric acid were dissolved in ultrapure water, which were afterwards successively dropped into LNMO solution with violent stirring. The solvent was evaporated at $80{ }^{\circ} \mathrm{C}$, followed by a drying process at $120{ }^{\circ} \mathrm{C}$. Finally, the black power was annealed at $400{ }^{\circ} \mathrm{C}$ for $4 \mathrm{~h}$ in Ar to form LVPO-LNMO (abbreviated as pristine, 0.5 wt. $\%, 1$ wt. $\%$ and 2 wt. $\%$ LVPO in the following discussion). For clear comparison, the as-prepared pristine sample also underwent the same treatment without adding any LVPO precursors (labeled as $0 \mathrm{wt} . \%$ ).

\subsection{Electrochemical measurements}

The electrode (cathode) sheets were composed of $80 \mathrm{wt} \%$ active material (as-prepared pristine, $0.5,1$ or $2 \mathrm{wt} . \%$ LVPO-LNMO), $10 \mathrm{wt} . \%$ acetylene black and 10 wt.\% PVDF (Polyvinylidene Fluoride), which were dissolved in N-methyl-2-pyrrolidone (NMP) solution to form a homogeneous slurry. Afterwards, the slurry was uniformly spread on an aluminum foil by a Four-side spreader and dried at $120{ }^{\circ} \mathrm{C}$ for $24 \mathrm{~h}$ in a vacuum drying chamber. Li-metal and Celgard 2400 were applied as counter electrode and separator to fabricate CR2032 coin type cells in an Ar-filled glove box (with $\mathrm{H}_{2} \mathrm{O}$ and $\mathrm{O}_{2}$ contents lower than 1 ppm). The electrolyte was $1 \mathrm{M} \mathrm{LiPF}_{6}$ dissolved in ethylene carbonate (EC) and dimethyl carbonate (DMC) (with 1:1 volume ratio). The electrochemical performances were evaluated via a Land test system (CT2001A, Wuhan, China) under the potential range of 3.5-4.9 V. Electrochemical impedance spectroscopy 
(EIS) test was conducted on an electrochemical workstation (CHI660E, Shanghai Chenhua) with applied $5 \mathrm{mV}$ sinusoidal perturbation in a frequency range over 5 $\mathrm{mHz}$ to $1 \mathrm{MHz}$ at room temperature (RT).

\subsection{Physical characterization}

The phase structures of the as-prepared powders were characterized by using X-ray diffraction (XRD) within a test 2 theta range of $10^{\circ}$ to $120^{\circ}$, and $\mathrm{Cu} \mathrm{K} \alpha$ as the radiation source $(\lambda=0.15418 \mathrm{~nm})$. Raman spectra were collected by the laser Raman spectrometer (RM-1000, Renishaw), equipped with a $632.8 \mathrm{~nm} \mathrm{He}-\mathrm{Ne}$ laser. The accurate element content analysis was carried out by an inductively coupled plasma spectrometer (ICP, Thermo Fisher ICAP 6300). The morphology of all products was detected by field emission-scanning electron microscopy (FESEM, JEOL JSM-7001F) coupled with energy dispersive spectroscopy (EDS), which was simultaneously collected on an APOLLO X silicon drift X-ray detector with a $15 \mathrm{kV}$ acceleration voltage. The high-resolution transmission electron microscopy (HRTEM) images were collected on FEI Tecnai F20 equipment. Surface chemistry environment was analyzed by using an X-ray photoelectron spectroscopy (XPS, ESCALAB 250, Sigma Probe, Thermo VG Scientific Co. Ltd) with monochromatized $\mathrm{Mg} \mathrm{K \alpha}$ source, and another equipment of XPS in-depth profile was performed with $\mathrm{Al} \mathrm{K} \alpha$ radiation $(50 \mathrm{~W}, 15 \mathrm{kV})$ at a pressure of $10^{-8}$ Torr (PHI 5000 Versa Probe-II, Japan), in which an argon ion beam etching 
process was employed at an accelerating voltage of $2.0 \mathrm{kV}$ and ion beam current density of $25 \mu \mathrm{A} \mathrm{mm}^{-2}$. The XPS data analysis was carried out by using XPS Peak 4.1 software. Differential scanning calorimetry (DSC) data of the pristine and LVPO-LNMO samples after stabilized at $4.9 \mathrm{~V}$ was measured on TA instrument (TA Q600) in Ar atmosphere with the scanning rate of $5^{\circ} \mathrm{C} \mathrm{min}^{-1}$ from RT to 350 ${ }^{\circ} \mathrm{C}$.

\section{Results and Discussion}

\subsection{Physical characterizations}

The morphologies of all as-prepared samples were characterized by SEM. With an invarible average particle size of $400 \mathrm{~nm}$, all the samples exhibit a typical feature of spinel structure with regular truncated octahedrons (Fig. $1 \mathrm{a}-\mathrm{b}$ and S1) ${ }^{46}$ It should be also noted that the particle surface of LVPO-LNMO becomes less smooth with increasing the LVPO content. More subtle information of the microstructures of pristine and LVPO-LNMO samples could be visualized from HRTEM images as shown in Fig. 1c-d. Both the pristine and 1wt.\% LVPO-LNMO exhibit good interior crystallinity with sharp fringes (lattice width $\sim 0.47 \mathrm{~nm}$ ), corresponding to the $\{111\}$ lattice plane in the octahedral LNMO with spinel structure. Distinctly, an amorphous layer with a thickness of $\sim 2 \mathrm{~nm}$ could be observed outside the $1 \mathrm{wt} . \%$ LVPO-LNMO particle, providing strong evidence for the generation of a surface modification layer. Besides, a gradually enhanced 
crystallization could be found from the corresponding fast Fourier transformation (FFT) patterns along the radical direction from surface to bulk (from the selected regions of I to III) in $1 \mathrm{wt}$ \% LVPO-LNMO, again proves the gradiently diffused V from coating layer to bulk interior. The EDS mapping results in Fig. 1f and S2 reveal the uniform distribution of $\mathrm{V}$ and $\mathrm{P}$ on the host particle, confirming the homogeneous modification of LVPO on the surface of pristine LNMO. By using ICP analysis, the contents of LVPO in 0.5, 1, 2 wt.\% LVPO-LNMO samples were determined to be $0.45,0.86,1.71$ wt. $\%$, respectively. All these results unexceptionally confirm that an amorphous LVPO layer have been successfully decorated on the surface of pristine LNMO (Fig. 1f).

Fig. 2 displays the XRD and Raman patterns of the pristine and LVPO-LNMO samples. As could be observed in Fig. 2a, all the samples are well crystallized, exhibiting a typical cubic spinel structure with a space group of Fd-3m, which is indexed to LNMO (JCPDS No. 80-2162). Since different annealing temperatures could be purposefully adopted in LNMO synthesis process, it is well-acknowledged that there are two different crystallographic structures of this material based on the ordering of TM cations. One is the ordered space group of $P 4332$, in which the $\mathrm{Mn}$ and $\mathrm{Ni}$ occupy the $12 d$ and $4 a$ sites, and the other one is the disordered space group of Fd-3m with a random distribution of Mn and $\mathrm{Ni}$ in the $16 d$ sites. ${ }^{47}$ The most remarkable difference between them is that some $\mathrm{Mn}^{3+}$ 
and oxygen vacancies are simultaneously existed in the disordered Fd-3m space group, which could efficiently improve the ionic and electronic conductivities of LNMO. ${ }^{13}$ In addition, the impurity phase of $\mathrm{Li}_{\mathrm{x}} \mathrm{Ni}_{1-\mathrm{x}} \mathrm{O}$ rock salt is generally found at $37.5^{\circ}, 43.7^{\circ}$ and $63.5^{\circ}$ for all the samples, derived from oxygen loss at a high annealing temperature over $700{ }^{\circ} \mathrm{C} .{ }^{48,49}$ Along with the increased modification contents, the diffraction profiles of LVPO-LNMO samples exhibit no obvious difference compared with that of the bare material (even in the right enlarged panel). To find the track of diffraction lines from LVPO, pure LVPO was also synthesized with a higher annealing temperature of $850{ }^{\circ} \mathrm{C}$, confirming the generation of this material under the same experimental condition (Fig. S3a). On the other hand, the LVPO signal is also absent in another LVPO-LNMO sample with rather high LVPO content (10 wt.\%, in Fig. S3b), indicating the essential amorphous feature of coated LVPO on the surface of as-prepared samples. Furthermore, the Rietveld refinement of XRD (Fig. 2a $\left.a_{1}-a_{4}\right)$ reveals the specific lattice parameters of LNMO before and after LVPO modification (Table S1). A linear parameter increase could be observed along with the content augment of LVPO, which could be attributed to the slight $\mathrm{V}$ migration from the LVPO modification layer to the LNMO surface lattice. Consequently, partial $\mathrm{Mn}^{4+}$ (with radius of $0.530 \AA$ ) could be reduced to $\mathrm{Mn}^{3+}(0.645 \AA)$ to compensate the valance in $\mathrm{V}$ diffusion process, resulting in the increase of lattice parameters. ${ }^{50}$ Moreover, compared with the pristine and $0 \mathrm{wt} . \%$ modified LNMO samples, it is found that 
the annealing process under Ar atmosphere brings more oxygen vacancies, along with more $\mathrm{Mn}^{3+}$ in $\mathrm{LNMO}^{51}$ All the XRD results confirm the existence of amorphous LVPO layer, and partial inner-side diffusion of V ions.

Meanwhile, all as-prepared samples present the typical Raman spectra of LNMO shown in Fig. 2b. Among all Raman peaks in the range from 100 to 800 $\mathrm{cm}^{-1}$, the $\mathrm{A}_{1 \mathrm{~g}}$ peak at $630 \mathrm{~cm}^{-1}$ is always assigned to the symmetric stretching vibration of $\mathrm{Mn}-\mathrm{O}$ bonds in $\mathrm{MnO}_{6}$ octahedral group. The $\mathrm{F}_{2 \mathrm{~g}}{ }^{(1)}$ at $387 \mathrm{~cm}^{-1}$ and the $\mathrm{F}_{2 \mathrm{~g}}{ }^{(2)}$ at $488 \mathrm{~cm}^{-1}$ are respectively ascribed to the stretching vibration modes of $\mathrm{Ni}-\mathrm{O}$ bonds in the spinel structure of LNMO material. ${ }^{52}$ Especially, the splitting of $\mathrm{T}_{2 \mathrm{~g}}{ }^{(3)}$ peak near $580-600 \mathrm{~cm}^{-1}$ is widely adopted to distinguish the order or disorder arrangement of LNMO.$^{53}$ Only one single $\mathrm{T}_{2 \mathrm{~g}}{ }^{(3)}$ peak is observed in each Raman curve of Fig. $2 \mathrm{~b}$, indicating that the Fd-3m disordered phase prevails in all the as-prepared materials with spinel structure. Though no remarkable difference in Reman shift and full width at half maximum (FWHM) could be observed among all the spectra (Fig. S4), implying little influence is brought from LVPO surface modification layer on the surface structure and component of LNMO, the vibration intensity gradually decays with increased LVPO stoichiometry, which could be ascribed to the masking effect of coated LVPO. ${ }^{54}$

To investigate the chemical environment of the material surface, XPS analysis was performed and the relevant results were shown in Fig. 3. Two unsymmetrical 
peaks appear at $\sim 643$ and $\sim 654 \mathrm{eV}$, which are usually assigned to the $\mathrm{Mn} 2 \mathrm{p}_{3 / 2}$ and $\mathrm{Mn} 2 \mathrm{p}_{1 / 2}$, respectively. Each region could be further fitted into two separate peaks based on the $\mathrm{MnO}_{2}$ and $\mathrm{Mn}_{2} \mathrm{O}_{3}$ standard spectral lines, as demonstrated in Fig. 3a-b and S5. The relative percentages of $\mathrm{Mn}^{3+}$ and $\mathrm{Mn}^{4+}$ in the surface range of each sample have been determined on the basis of the peak areas (Fig. $3 \mathrm{c}$ and Table S2). With increasing the stoichiometry of LVPO, the amount of $\mathrm{Mn}^{3+}$ displays a distinct monotonous augment from $63 \%$ to $75 \%$, whereas that of $\mathrm{Mn}^{4+}$ shrinks from $37 \%$ to $25 \%$, coinciding with the XRD analysis. It should also be noted that the Ni $2 p_{3 / 2}(854.6 \mathrm{eV})$ experience no obvious shift compared with bare LNMO sample, implying that the $\mathrm{Ni}^{2+}$ is not involved in the valence compensation in the LVPO modification process. Besides, it could be noticed that the P $2 \mathrm{p}_{3 / 2}$ $(134 \mathrm{eV})$ and $\mathrm{V} 2 \mathrm{p}_{1 / 2}(517 \mathrm{eV})$ signals are remarkably enhanced along with the attenuation of Ni intensities (Fig. S6), providing another strong evidence of LVPO modification on the surface of LNMO..$^{55-57}$

To obtain more insight into the migration of V ions in LNMO, XPS sputtered depth profiles of the $\mathrm{V} 2 \mathrm{p}$ and the Mn $2 \mathrm{p}$ signals were simultaneously detected from the surface to the interior of the $1 \mathrm{wt} . \%$ LVPO-LNMO sample. According to the signal intensity and normalized results shown in Fig. 3d-f, as expected, the signal intensity of $\mathrm{Mn} 2 \mathrm{p}$ gradually enhance along with etching time. Simultaneously, that of the V $2 p$ becomes weaker from surface to the interior part. 
These results undoubtedly provide a direct evidence of $\mathrm{V}$ gradient doping on the surface of LNMO.

\subsection{Electrochemical measurements}

To demonstrate the influence of the LVPO modification layer on the electrochemical performances of LNMO, electrochemical properties were intensively characterized and analyzed. All samples were firstly tested at a low current rate $(0.1 \mathrm{C})$ in the voltage range of 3.5-4.9 V at RT. As shown in Fig. 4a, all electrodes show similar initial specific capacities of 125.4, 124.7, 124.2 and 121.7 $\mathrm{mAh} \mathrm{g}^{-1}$, respectively. Remarkably, the LVPO-LNMO samples exhibit improved long-cycle stabilities than the pristine electrode, in which the $1 \mathrm{wt} . \%$ LVPO-LNMO sample delivers the highest capacity retention of $87.8 \%$ even after 500 cycles, significantly higher than those of the pristine, 0.5 and 2 wt.\% LVPO-LNMO samples $(25.6 \%, 64.1 \%$ and $35.8 \%$, respectively). Meanwhile, the initial coulombic efficiency of 1 wt.\% LVPO-LNMO could reach $86.7 \%$, prevailing over those of the other three electrodes $(79.6 \%, 84.3 \%$ and $81.9 \%$, respectively). Fig. 4b shows the typical charge-discharge curves of all samples in the initial cycling. It could be observed that all cathodes manifest a short plateau at $\sim 4.0 \mathrm{~V}$, which is originated from the oxidation of $\mathrm{Mn}^{3+}$ to $\mathrm{Mn}^{4+}$ in the disordered Fd-3m space group. Besides, the presence of the voltage plateau and the redox in $\mathrm{dQ} / \mathrm{dV}$ curves at $\sim 4.0 \mathrm{~V}$ could be attributed to the $\mathrm{Mn}^{3+} / \mathrm{Mn}^{4+}$ redox, which is 
more prominent in the LVPO-LNMO samples compared with the pristine electrode (Fig. 4b-c), confirming the augmented $\mathrm{Mn}^{3+}$ content with the increase of LVPO proportion among the as-prepared samples. This finding is in corresponding to the previous HRTEM, XRD and XPS analysis. Previous studies proved that more $\mathrm{Mn}^{3+}$ could efficiently improve $\mathrm{Li}^{+}$transmission dynamics. ${ }^{58}$ Further analysis indicates that the $\mathrm{Ni}^{2+} / \mathrm{Ni}^{3+}$ and $\mathrm{Ni}^{3+} / \mathrm{Ni}^{4+}$ redox pairs display the less prominent polarizations (i.e. enhanced kinetics) in $1 \mathrm{wt} . \%$ LVPO-LNMO compared with the pristine sample, with the D-values decreased from 0.04 to $0.01 \mathrm{~V}$ (Fig. 4c, Table S3), which partly explains the strong electrochemical reversibility in Fig. 4a for the electrode of 1 wt.\% LVPO-LNMO. Fig. 4d, the measurement of rate performances reveals a significant enhancement in discharge capacities for 1 wt.\% LVPO-LNMO, especially at high current rates (from $1 \mathrm{C}$ to $20 \mathrm{C}, 1 \mathrm{C}=147 \mathrm{~mA}$ $\left.\mathrm{g}^{-1}\right)$. When cycled at $20 \mathrm{C}$, the $1 \mathrm{wt} . \%$ LVPO-LNMO delivers a capacity of 90.4 $\mathrm{mAh} \mathrm{g}^{-1}$, much higher than that of the others electrode at the same current density (26.6, 72.4 and $45.3 \mathrm{mAh} \mathrm{g}^{-1}$, respectively). Therefore, the $1 \mathrm{wt} \%$ LVPO-LNMO sample exhibits more superior rate capability and cycle reversibility than the pristine, 0.5 and 2 wt.\% LVPO-LNMO materials.

As graphed in Fig. 4e and Fig. S7, even at an elevated temperature of $55{ }^{\circ} \mathrm{C}$, the 1 wt.\% LVPO-LNMO sample still displays improved initial discharge capacity and coulombic efficiency capacity than those of the pristine sample $\left(121 \mathrm{mAh} \mathrm{g}^{-1}\right.$ 
and $74.1 \%$ vs.102.7 $\mathrm{mAh} \mathrm{g}^{-1}$ and $46.1 \%$ ). Additionally, though both samples show fast capacity decay, resulted from the aggravated TM ion dissolution and surface side-reactions at elevated temperature, the $1 \mathrm{wt} . \%$ LVPO-LNMO exhibits a longer cycle life than that of the pristine material, implying the LVPO surface modification helps to stabilize the material structure.

To elucidate the specific effect of LVPO modification layer on the $\mathrm{Li}^{+}$ diffusion kinetics, the EIS measurement of the pristine and 1 wt.\% LVPO-LNMO samples were carried out at the charged state of $4.9 \mathrm{~V}$ after different cycles. The Nyquist plots are presented in Fig. 5a-b, demonstrating two semicircles in high and middle frequency ranges and an inclined line in the low frequency region. The corresponding equivalent circuit is shown in Fig. $5 c$, in which $\mathrm{R}_{1}$ represents the intercept in the high frequency range (Ohmic resistance), $R_{s f}$ in high frequency region and $\mathrm{R}_{\mathrm{ct}}$ in medium frequency region are correspond to the $\mathrm{Li}^{+}$diffusion in the cathode-electrolyte interface film (CEI resistance) and space charge layer (charge transfer resistance) ${ }^{59}$ Besides, the inclined line in the low frequency range is attributed to the Warburg impedance $\left(\mathrm{W}_{1}\right)$, reflecting the solid-state diffusion of $\mathrm{Li}^{+}$ions in the bulk of the electrode material. ${ }^{60}$

From Fig. 5a-b, it could be observed that the semicircles in both high and medium frequency regions could be significantly depressed by 1 wt.\% LVPO surface modification. The fitted EIS values of $\mathrm{R}_{\mathrm{ct}}$ and $\mathrm{R}_{\mathrm{sf}}$ for the two electrodes are 
shown in Fig. 5e and Table 1, quantitatively confirming the remarkable resistance depression for the 1 wt.\% LVPO-LNMO sample under the electrochemical treatment. The smaller $\mathrm{R}_{\mathrm{sf}}$ value suggests the LVPO modification layer could effectively alleviate side reactions at the interface between electrode and electrolyte, and consequently, suppress the generation of CEI film on the electrode surface. On the other hand, the drastically reduced $R_{c t}$ could be ascribed to the transition layer generated between the coated LVPO and bulk LNMO (Li-Ni-Mn-V-O surface solid solution). Therefore, the LVPO surface modification could efficiently improve the kinetics behavior of $\mathrm{Li}^{+}$intercalation/deintercalation in the cathode during the charge-recharge process. ${ }^{61,62}$

The $\mathrm{Li}^{+}$diffusion coefficient $\left(D_{\mathrm{Li}}\right)$ was calculated from the EIS plots in the low frequency region according to the following equations:

$$
\begin{gathered}
Z_{\text {real }}=K-\delta \omega^{-1 / 2}(1) \\
D_{L i}=0.5\left(\frac{R T}{A F^{2} \delta C_{L i}}\right)^{2}
\end{gathered}
$$

wherein $K$ is a constant, $\omega$ is the angular frequency region, $\sigma$ is the Warburg factor, $R$ is the gas constant, $T$ is the absolute temperature, $F$ is the Faraday's constant, $A$ is the area of electrode surface, $C_{L i}$ is the molar concentration of $\mathrm{Li}^{+}$. Among them, the values of Warburg factor $\sigma$ are correspond to the plot slopes of $\sigma$ against $\omega^{-1 / 2}$, which are shown in Fig. $5 d$. Thus, the $D_{\mathrm{Li}}$ values of the pristine and 
1 wt.\% LVPO-LNMO samples after 60 charge-discharge cycles are calculated to be $4.5 \times 10^{-12} \mathrm{~cm}^{2} \mathrm{~s}^{-1}$ and $1.3 \times 10^{-9} \mathrm{~cm}^{2} \mathrm{~s}^{-1}$ based on Eq. (2), clearly indicating that the diffusion coefficient of $\mathrm{Li}^{+}$ions in LNMO electrode could be dramatically enhanced through LVPO surface modification in the present work. This result undoubtedly interprets the notably enhanced rate capability of modified electrode in Fig. 4d.

\subsection{Chemical and electrochemical aging tests}

To further clarify the fundamental roles of LVPO modification, chemical and electrochemical aging measurements were conducted on both pristine and 1 wt.\% LVPO-LNMO samples. Firstly, SEM and XRD tests were carried out for the two electrode slices after 150 cycles at elevated temperature $\left(55^{\circ} \mathrm{C}\right)$, and the results were compared in Fig. S7. It is clear that the morphology of the pristine particle has been seriously deteriorated, along with the deposition of a dense CEI layer generated of drastic

HF attack from the electrolyte. ${ }^{63}$ Moreover, the exposed surface of the pristine LNMO particles accelerates the dissolution of TM ions at elevated temperature. All these result in the structure collapse of bare LNMO, as proved by the XRD pattern in Fig. S7c. The intensities of $\{111\},\{311\}$ and $\{400\}$ diffraction peaks of the pristine sample are sharply declined, accompanied by some disappeared or broadened peaks. While as for the XRD pattern of the 1 wt.\% LVPO-LNMO sample, no obvious change could be found for all diffraction peaks after electrochemical treatment (Fig. 2a). 
Additionally, the chemical aging experiments were performed for the pristine and 1 wt.\% LVPO-LNMO powders. The two arid samples with the same mass were soaked in the same kind of commercial electrolyte, followed by thorough solid-liquid separation and characterizations of XRD, Raman, ICP and SEM tests along with aging time. The colour of separated liquid gradually deepens for the pristine soaking system, which is presumably ascribed to the dissolution of TM ions in LNMO active material, which is confirmed through the ICP analysis in its solid counterpart. As compared in Fig. 6b and Table S4, the concentrations of TM ions ( $\mathrm{Mn}$ and $\mathrm{Ni}$ ) in the pristine and 1 wt.\% LVPO-LNMO samples with different aging time are compared, from which the contents of $\mathrm{Mn}$ and $\mathrm{Ni}$ ions are simultaneously reduced with aging time in both samples. While distinctly, the dissolution of TM ions in LVPO-LNMO sample is less prominent than that in the pristine material. All these results suggest that the LVPO modification layer helps to alleviate the TM dissolution and stabilize the structure of LNMO. The stabilized structure could also be deduced by the XRD analysis in Fig. S8a. As could be observed in this part, strong LiMnO impurity phase could be identified in aged pristine LNMO, suggesting significant structure degradation of this material. While comparatively, the LVPO modified LNMO undergoes negligible change in its diffraction lines, even with three or four weeks soakage, which reflects its robust structure stability with LVPO modification layer. The suppression of LNMO structure degradation by LVPO modification could also be supported by 
Raman and SEM characterizations. The intensities of Raman vibrations are obviously weakened for pristine LNMO with aging time (Fig. S8b), and serious corrosion gradually appears on the surface of it (Fig. 6c). While the LVPO decorated sample, with stabilized structure, demonstrates rather stable signals both in Raman and SEM.

All the above aging results suggest that the integrated modification layer could effectively enhance the surface and bulk structure stability of LNMO. Not only the TM ions dissolution could be suppressed to stabilize the bulk material, but the particle surface could also be passivated to avoiding severe HF corrosion.

As one of an important evaluation parameter for the electrode materials, thermal safety has been paid more and more attention in commercial applications for LIBs. ${ }^{64}$ DSC traces of the pristine and $1 \mathrm{wt} . \%$ LVPO-LNMO samples were measured and shown in Fig. S9. Exothermic peak of the 1 wt.\% LVPO-LNMO sample is shifted to $311^{\circ} \mathrm{C}$, much higher than that of the pristine sample $\left(250{ }^{\circ} \mathrm{C}\right)$. Besides, the released heat is significantly alleviated after LVPO surface modification (Fig. S9, inset). The above results clearly reveal that LVPO modification layer contribute greatly in suppressing the exothermic reaction in electrochemical environment, and consequently improves the thermal safety of the modified electrode. ${ }^{65}$

\subsection{Mechanism discussion}


From the above analysis, the enhancement mechanism for LVPO surface modification could be summarized as follows (Scheme 2):

First, as one of the fast ion conductor materials, LVPO modification layer could obviously facilitate the $\mathrm{Li}^{+}$diffusion kinetics at the interface of electrode and electrolyte. Meanwhile, it could also effectively protect the surface of bulk LNMO from being attacked by electrolyte during electrochemical cycling under room or elevated temperatures, which attributes to the significantly depressed side-reactions and the growth of CEI film (decreased $\mathrm{R}_{\mathrm{sf}}$ ).

Second, a facile one-step annealing process in Ar atmosphere stimulates the gradient doping of $\mathrm{V}$ ions into the surface lattice of LNMO, finally generating V-involved Li-Ni-Mn-V-O surface solid solution as a transition layer to integrate the coated LVPO and the LNMO material (reduced $\mathrm{R}_{\mathrm{ct}}$ ).

From the viewpoint of structure stability, the integrated LVPO modification layer could stabilize the material structure by suppressing the dissolution of TM ions from interior lattice of LNMO, remitting the Jahn-Teller distortion and disproportionation reaction, as well as promoting the thermal stability of the as-prepared LVPO-LNMO used as cathode materials. ${ }^{66}$ From another aspect, the as-prepared LVPO-LNMO exhibits enlarged lattice parameters and increased $\mathrm{Mn}^{3+}$ content, which also explains the enhanced $\mathrm{Li}^{+}$kinetics behaviour. 


\section{Conclusion}

In summary, the fast-ion conductor of LVPO was utilized to modify the surface of spinel LNMO via a simple sol-gel method and a final thermal treatment at $400{ }^{\circ} \mathrm{C}$. It shows that the electrochemical properties (long cycling performances at both room and elevated temperatures, as well as rate capabilities) and thermal stability of LNMO materials could be significantly enhanced, with an optimized LVPO modification content of $1 \mathrm{wt} . \%$. Further investigations indicate that the LVPO modification layer, which not only facilitates the $\mathrm{Li}^{+}$diffusion on the material surface through suppressing the growth of CEI layer, but also benefits for the $\mathrm{Li}^{+}$ transportation at the interface of LNMO bulk material and LVPO layer via the generation of Li-Ni-Mn-V-O surface solid solution as a packing layer. Besides, the integrated LVPO surface modification layer could help to stabilize the LNMO structure in alleviating the dissolution of TM ions and enhance the diffusion kinetics in the bulk. Therefore, the one-step integrated surface modification proposed herein not only paves the way to more comprehensive and convenient modification strategy for electrode construction with better properties for secondary batteries, including $\mathrm{Li}^{+}, \mathrm{Na}^{+}, \mathrm{K}^{+}, \mathrm{Mg}^{2+}, \mathrm{Al}^{3+}, \mathrm{Li}-\mathrm{S}$ and $\mathrm{Li}-\mathrm{O}$ batteries, but also sheds light in more in-depth mechanism exploration and broad application in a wide range of electrochemical systems as well as the community of surface/interface decorations. 


\section{Conflicts of interest}

There are no conflicts to declare.

\section{Acknowledgements}

This work was supported by the National Natural Science Foundation of China (50902044, 51672069, 10674041, 11704019), the 863 Program of China (2015AA034201), the Program for Science and Technology Innovation Talents in Universities of Henan Province (16HASTIT042), Foundation of Henan Educational Committee (18A140001) and the International Cooperation Project of Science and Technology Department of Henan Province (162102410014).

\section{References}

(1) Cano, Z. P.; Banham, D.; Ye, S.; Hintennach, A.; Lu, J.; Fowler, M.; Chen, Z., Batteries and fuel cells for emerging electric vehicle markets. Nat. Energy 2018, 3, 279-289;

(2) Lu, J.; Chen, Z.; Ma, Z.; Pan, F.; Curtiss, L. A.; Amine, K., The role of nanotechnology in the development of battery materials for electric vehicles. Nature Nanotech. 2016, 11, 1031-1038.

(3) Zhao, L. Z.; Wu, H. H.; Yang, C. H.; Zhang, Q. B.; Zhong, G. M.; Zheng, Z. M.; Chen, H. X.; Wang, J. M.; He, K.; Wang, B. L.; Zhu, T.; Zeng, X. C.; Liu, M. L.; Wang, M. S., 
Mechanistic origin of the high performance of yolk@shell Bi $\mathrm{S}_{3} @ \mathrm{~N}$-doped carbon nanowire electrodes. ACS Nano 2018, 12, 12597-12611.

(4) Deng, Y. F.; Zhao, S. X.; Xu, Y. H.; Gao, K.; Nan, C. W., Impact of P-Doped in spinel $\mathrm{LiNi}_{0.5} \mathrm{Mn}_{1.5} \mathrm{O}_{4}$ on degree of disorder, grain morphology, and electrochemical performance. Chem. Mater. 2015, 27, 7734-7742.

(5) Chong, J.; Zhang, J.; Xie, H.; Song, X.; Liu, G.; Battaglia, V.; Xun, S.; Wang, R., High performance $\mathrm{LiNi}_{0.5} \mathrm{Mn}_{1.5} \mathrm{O}_{4}$ cathode material with a bi-functional coating for lithium ion batteries. $R S C A d v$. 2016, 6, 19245-19251.

(6) Boesenberg, U.; Falk, M.; Ryan, C. G.; Kirkham, R.; Menzel, M.; Janek, J.; Fröba, M.; Falkenberg, G.; Fittschen, U. E. A., Correlation between chemical and morphological heterogeneities in $\mathrm{LiNi}_{0.5} \mathrm{Mn}_{1.5} \mathrm{O}_{4}$ spinel composite electrodes for lithium-ion batteries determined by micro-X-ray fluorescence analysis. Chem. Mater. 2015, 27, 2525-2531;

(7) Santhanam, R.; Rambabu, B., Research progress in high voltage spinel $\mathrm{LiNi}_{0.5} \mathrm{Mn}_{1.5} \mathrm{O}_{4}$ material. J. Power Sources 2010, 195, 5442-5451.

(8) Manthiram, A.; Chemelewski, K.; Lee, E. S., A perspective on the high-voltage $\mathrm{LiNi}_{0.5} \mathrm{Mn}_{1.5} \mathrm{O}_{4}$ spinel cathode for lithium-ion batteries. Energy Environ. Sci. 2014, 7 , 1339-1350.

(9) Ma, J.; Hu, P.; Cui, G.; Chen, L., Surface and interface issues in spinel $\mathrm{LiNi}_{0.5} \mathrm{Mn}_{1.5} \mathrm{O}_{4}$ : insights into a potential cathode material for high energy density lithium ion batteries. 
Chem. Mater. 2016, 28, 3578-3606;

(10) Wang, K. X.; Li, X. H.; Chen, J. S., Surface and interface engineering of electrode materials for lithium-ion batteries. Adv. Mater. 2015, 27, 527-45.

(11) Nowak, S.; Winter, M., The role of cations on the performance of lithium ion batteries: a quantitative analytical approach. Acc. Chem. Res. 2018, 51, 265-272.

(12) Xiao, B.; Liu, J.; Sun, Q.; Wang, B.; Banis, M. N.; Zhao, D.; Wang, Z.; Li, R.; Cui, X.; Sham, T. K.; Sun, X., Unravelling the role of electrochemically active $\mathrm{FePO}_{4}$ coating by atomic layer deposition for increased high-voltage stability of $\mathrm{LiNi}_{0.5} \mathrm{Mn}_{1.5} \mathrm{O}_{4}$ cathode material. Adv. Sci. 2015, 2, 1500022.

(13) Tian, C.; Lin, F.; Doeff, M. M., Electrochemical characteristics of layered transition metal oxide cathode materials for lithium ion batteries: surface, bulk behavior, and thermal properties. Acc. Chem. Res. 2018, 51, 89-96.

(14) Li, W.; Liu, X.; Celio, H.; Smith, P.; Dolocan, A.; Chi, M.; Manthiram, A., Mn versus $\mathrm{Al}$ in layered oxide cathodes in lithium-ion batteries: a comprehensive evaluation on long-term cyclability. Adv. Energy Mater. 2018, 8, 1703154.

(15) Li, Y.; Zhang, Q.; Xu, T.; Wang, D.; Pan, D.; Zhao, H.; Bai, Y., $\mathrm{LaF}_{3}$ nanolayer surface modified spinel $\mathrm{LiNi}_{0.5} \mathrm{Mn}_{1.5} \mathrm{O}_{4}$ cathode material for advanced lithium-ion batteries. Cera. Int. 2018, 44, 4058-4066.

(16) Zheng, J.; Gu, M.; Xiao, J.; Polzin, B. J.; Yan, P.; Chen, X.; Wang, C.; Zhang, J. G., 
Functioning mechanism of $\mathrm{AlF}_{3}$ coating on the Li- and Mn-rich cathode materials. Chem. Mater. 2014, 26, 6320-6327.

(17) Shapira, A.; Tiurin, O.; Solomatin, N.; Auinat, M.; Meitav, A.; Ein-Eli, Y., Robust $\mathrm{AlF}_{3}$ atomic layer deposition protective coating on $\mathrm{LiMn}_{1.5} \mathrm{Ni}_{0.5} \mathrm{O}_{4}$ particles: an advanced Li-ion battery cathode material powder. ACS Appl. Energy Mater. 2018, 1, 6809-6823.

(18) Xu, T.; Li, Y.; Wang, D.; Wu, M.; Pan, D.; Zhao, H.; Bai, Y., Enhanced electrochemical performance of $\mathrm{LiNi}_{0.5} \mathrm{Mn}_{1.5} \mathrm{O}_{4}$ cathode material by $\mathrm{YPO}_{4}$ surface modification. ACS Sustainable Chem. Eng. 2018, 6, 5818-5825.

(19) Liu, Y. J.; Fan, X. J.; Zhang, Z. Q.; Wu, H. H.; Liu, D. M.; Dou, A.; Su, M. R.; Zhang, Q. B.; Chu, D. W., Enhanced electrochemical performance of Li-rich layered cathode materials by combined $\mathrm{Cr}$ doping and $\mathrm{LiAlO}_{2}$ coating. ACS Sustainable Chem. Eng. 2019, 7, 2225-2235.

(20) Zhao, J. Z.; Liu, Y. R.; He, Y.; Lu, K., $\mathrm{Li}_{4} \mathrm{Ti}_{5} \mathrm{O}_{12}$ epitaxial coating on $\mathrm{LiNi}_{0.5} \mathrm{Mn}_{1.5} \mathrm{O}_{4}$ surface for improving the electrochemical performance through solvothermal-assisted processing. J. Alloys Compd. 2019, 779, 978-984.

(21) Wang, D.; Zhang, X.; Xiao, R.; Lu, X.; Li, Y.; Xu, T.; Pan, D.; Hu, Y. S.; Bai, Y., Electrochemical performance of Li-rich $\mathrm{Li}\left[\mathrm{Li}_{0.2} \mathrm{Mn}_{0.56} \mathrm{Ni}_{0.17} \mathrm{Co}_{0.07}\right] \mathrm{O}_{2}$ cathode stabilized by metastable $\mathrm{Li}_{2} \mathrm{SiO}_{3}$ surface modification for advanced Li-ion batteries. Electrochim. Acta 2018, 265, 244-253. 
(22) Kuganathan, N.; Kordatos, A.; Chroneos, A., $\mathrm{Li}_{2} \mathrm{SnO}_{3}$ as a cathode material for lithium-ion batteries: defects, lithium ion diffusion and dopants. Sci. Rep. 2018, 8, 12621.

(23) Dong, H. Y.; Zhang, Y. J.; Zhang, S. Q.; Tang, P. P.; Xiao, X. L.; Ma, M. Y.; Zhang, H. S.; Yin, Y. H.; Wang, D.; Yang, S. T., Improved high temperature performance of a spinel $\mathrm{LiNi}_{0.5} \mathrm{Mn}_{1.5} \mathrm{O}_{4}$ cathode for high-voltage lithium-ion batteries by surface modification of a flexible conductive nanolayer. ACS Omega 2019, 4, 185-194.

(24) Deng, J. C.; Xu, Y. L.; Li, L.; Feng, T. Y.; Li, L., Microporous $\mathrm{LiAlSiO}_{4}$ with high ionic conductivity working as a coating material and water adsorbent for $\mathrm{LiNi}_{0.5} \mathrm{Mn}_{1.5} \mathrm{O}_{4}$ cathode. J. Mater. Chem. A 2016, 4, 6561-6568.

(25) Yi, T. F.; Han, X.; Chen, B.; Zhu, Y. R.; Xie, Y., Porous sphere-like $\mathrm{LiNi}_{0.5} \mathrm{Mn}_{1.5} \mathrm{O}_{4}-\mathrm{CeO}_{2}$ composite with high cycling stability as cathode material for lithium-ion battery. J. Alloys Compd. 2017, 703, 103-113.

(26) Sun, P.; Ma, Y.; Zhai, T.; Li, H., High performance $\mathrm{LiNi}_{0.5} \mathrm{Mn}_{1.5} \mathrm{O}_{4}$ cathode by Al-coating and $\mathrm{Al}^{3+}$-doping through a physical vapor deposition method. Electrochim. Acta 2016, 191, 237-246.

(27) Luo, Y.; Lu, T.; Zhang, Y.; Yan, L.; Mao, S. S.; Xie, J., Surface-segregated, high-voltage spinel lithium-ion battery cathode material $\mathrm{LiNi}_{0.5} \mathrm{Mn}_{1.5} \mathrm{O}_{4}$ cathodes by aluminium doping with improved high-rate cyclability. J. Alloys Compd. 2017, 703, 289-297. 
(28) Wang, J.; Nie, P.; Xu, G. Y.; Jiang, J. M.; Wu, Y. T.; Fu, R. R.; Dou, H.; Zhang, X. G., High-voltage $\mathrm{LiNi}_{0.5} \mathrm{Mn}_{1.5} \mathrm{O}_{4}$ cathode with superlong cycle performance for wide temperature lithium-ion batteries. Adv. Funct. Mater. 2018, 28, 1704808.

(29) Nageswaran, S.; Keppeler, M.; Kim, S. J.; Srinivasan, M., Morphology controlled Si-modified $\mathrm{LiNi}_{0.5} \mathrm{Mn}_{1.5} \mathrm{O}_{4}$ microspheres as high performance high voltage cathode materials in lithium ion batteries. J. Power Sources 2017, 346, 89-96.

(30) Feng, S.; Kong, X.; Sun, H.; Wang, B.; Luo, T.; Liu, G., Effect of Zr doping on $\mathrm{LiNi}_{0.5} \mathrm{Mn}_{1.5} \mathrm{O}_{4}$ with ordered or disordered structures. J. Alloys Compd. 2018, 749, 1009-1018;

(31) Kim, M. C.; Nam, K. W.; Hu, E.; Yang, X. Q.; Kim, H.; Kang, K.; Aravindan, V.; Kim, W. S.; Lee, Y. S., Sol-gel synthesis of aliovalent vanadium-doped $\mathrm{LiNi}_{0.5} \mathrm{Mn}_{1.5} \mathrm{O}_{4}$ cathodes with excellent performance at high temperatures. ChemSusChem 2014, 7, $829-834$.

(32) Wang, H.; Ben, L.; Yu, H.; Chen, Y.; Yang, X.; Huang, X., Understanding the effects of surface reconstruction on the electrochemical cycling performance of the spinel $\mathrm{LiNi}_{0.5} \mathrm{Mn}_{1.5} \mathrm{O}_{4}$ cathode material at elevated temperatures. J. Mater. Chem. A 2017, 5, $822-834$.

(33) Piao, J. Y.; Sun, Y. G.; Duan, S. Y.; Cao, A. M.; Wang, X. L.; Xiao, R. J.; Yu, X. Q.; Gong, Y.; Gu, L.; Li, Y.; Liu, Z. J.; Peng, Z. Q.; Qiao, R. M.; Yang, W. L.; Yang, X. Q.; 
Goodenough, J. B.; Wan, L. J., Stabilizing cathode materials of lithium-ion batteries by controlling interstitial sites on the surface. Chem, 2018, 4, 1685-1695.

(34) Li, L. J.; Chen, Z. Y.; Zhang, Q. B.; Xu, M.; Zhou, X.; Zhu, H.; Zhang, K. L., A hydrolysis-hydrothermal route for the synthesis of ultratin $\mathrm{LiAlO}_{2}$-inlaid $\mathrm{LiNi}_{0.5} \mathrm{Co}_{0.2} \mathrm{Mn}_{0.3} \mathrm{O}_{2}$ as a high-performance cathode material for lithium ion batteries. $J$. Mater. Chem. A, 2015, 3, 894-904.

(35) Yan, P.; Zheng, J.; Liu, J.; Wang, B.; Cheng, X.; Zhang, Y.; Sun, X.; Wang, C.; Zhang, J. G., Tailoring grain boundary structures and chemistry of Ni-rich layered cathodes for enhanced cycle stability of lithium-ion batteries. Nat. Energy 2018, 3, 600-605.

(36) Wang, D.; Xu, T.; Li, Y.; Pan, D.; Lu, X.; Hu, Y. S.; Dai, S.; Bai, Y., Integrated surface functionalization of Li-rich cathode materials for Li-ion batteries. ACS Appl. Mater. Interfaces 2018, 10, 41802-41813.

(37) Xiao, J.; Chen, X.; Sushko, P. V.; Sushko, M. L.; Kovarik, L.; Feng, J.; Deng, Z.; Zheng, J.; Graff, G. L.; Nie, Z.; Choi, D.; Liu, J.; Zhang, J.-G.; Whittingham, M. S., High-performance $\mathrm{LiNi}_{0.5} \mathrm{Mn}_{1.5} \mathrm{O}_{4}$ spinel controlled by $\mathrm{Mn}^{3+}$ concentration and site disorder. Adv. Mater. 2012, 24, 2109-2116.

(38) Yang, H. P.; Wu, H. H.; Ge, M. Y.; Li, L. J.; Yuan, Y. F.; Yao, Q.; Chen, J.; Xia, L. F.; Zheng, J. M.; Chen, Z. Y.; Duan, J. F.; Kisslinger, K.; Zeng, X. C.; Lee, W. K.; Zhang, Q. 
B.; Lu, J., Simultaneously dual modification of Ni-rich layered oxide cathode for high-energy lithium-ion batteries. Adv. Funct. Mater. 2019, 1808825.

(39) Oh, G.; Hirayama, M.; Kwon, O.; Suzuki, K.; Kanno, R., Bulk-type all solid-state batteries with $5 \mathrm{~V}$ class $\mathrm{LiNi}_{0.5} \mathrm{Mn}_{1.5} \mathrm{O}_{4}$ cathode and $\mathrm{Li}_{10} \mathrm{GeP}_{2} \mathrm{~S}_{12}$ solid electrolyte. Chem. Mater. 2016, 28, 2634-2640.

(40) Liu, B.; Zhang, J. G.; Xu, W., Advancing lithium metal batteries. Joule 2018, 2, 833-845.

(41) He, X.; Zhu, Y.; Mo, Y., Origin of fast ion diffusion in super-ionic conductors. Nat. Commun. 2017, 8, 15893.

(42) Zhu, Y. R,; Yi, T. F.; Li, X. Y.; Xie, Y.; Luo, S. H., Improved rate performance of $\mathrm{LiNi}_{0.5} \mathrm{Mn}_{1.5} \mathrm{O}_{4}$ as cathode of lithium-ion battery by $\mathrm{Li}_{0.33} \mathrm{La}_{0.56} \mathrm{TiO}_{3}$ coating. Mater. Lett. 2019, 239, 56-58.

(43) Tan, H.T.; Xu, L. H.; Geng, H. B.; Rui, X. H.; Li, C. C.; Huang, S. M., Nanostructured $\mathrm{Li}_{3} \mathrm{~V}_{2}\left(\mathrm{PO}_{4}\right)_{3}$ cathodes. Small 2018, 14, 1800567.

(44) Gao, Z.; Sun, H.; Fu, L.; Ye, F.; Zhang, Y.; Luo, W.; Huang, Y., Promises, challenges, and recent progress of inorganic solid-state electrolytes for all-solid-state lithium batteries. Adv. Mater. 2018, 30, 1705702.

(45) Chen, B.; Ben, L.; Chen, Y.; Yu, H.; Zhang, H.; Zhao, W.; Huang, X., Understanding the formation of the truncated morphology of high-voltage spinel $\mathrm{LiNi}_{0.5} \mathrm{Mn}_{1.5} \mathrm{O}_{4}$ via 
direct atomic-level structural observations. Chem. Mater. 2018, 30, 2174-2182.

(46) Banerjee, A.; Shilina, Y.; Ziv, B.; Ziegelbauer, J. M.; Luski, S.; Aurbach, D.; Halalay, I. C., On the oxidation state of manganese ions in Li-ion battery electrolyte solutions. $J$. Am. Chem. Soc. 2017, 139, 1738-1741.

(47) Liu, H.; Wang, J.; Zhang, X.; Zhou, D.; Qi, X.; Qiu, B.; Fang, J.; Kloepsch, R.; Schumacher, G.; Liu, Z.; Li, J., Morphological evolution of high-voltage spinel $\mathrm{LiNi}_{0.5} \mathrm{Mn}_{1.5} \mathrm{O}_{4}$ cathode materials for lithium-ion batteries: the critical effects of surface orientations and particle size. ACS Appl. Mater. Interfaces 2016, 8, 4661-75.

(48) Xu, C. L.; Xiang, W.; Wu, Z. G.; Li, Y. C.; Xu, Y. D.; Hua, W. B.; Guo, X. D.; Zhang, X. B.; Zhong, B. H., A comparative study of crystalline and amorphous $\mathrm{Li}_{0.5} \mathrm{La}_{0.5} \mathrm{TiO}_{3}$ as surface coating layers to enhance the electrochemical performance of $\mathrm{LiNi}_{0.815} \mathrm{Co}_{0.15} \mathrm{Al}_{0.035} \mathrm{O}_{2}$ cathode. J. Alloys Compd. 2018, 740, 428-435.

(49) Lee, J.; Kitchaev, D. A.; Kwon, D. H.; Lee, C. W.; Papp, J. K.; Liu, Y. S.; Lun, Z.; Clement, R. J.; Shi, T.; McCloskey, B. D.; Guo, J.; Balasubramanian, M.; Ceder, G., Reversible $\mathrm{Mn}(2+) / \mathrm{Mn}(4+)$ double redox in lithium-excess cathode materials. Nature 2018, 556, 185-190.

(50) Wang, Z.; Su, Q.; Deng, H.; Fu, Y., Oxygen Deficiency and Defect Chemistry in Delithiated spinel $\mathrm{LiNi}_{0.5} \mathrm{Mn}_{1.5} \mathrm{O}_{4}$ cathodes for li-ion batteries. ChemElectroChem 2015, 2, $1182-1186$. 
(51) Zhao, Y.; Liu, J.; Wang, S.; Ji, R.; Xia, Q.; Ding, Z.; Wei, W.; Liu, Y.; Wang, P.; Ivey, D. G., Surface structural transition induced by gradient polyanion-doping in Li-rich layered oxides: implications for enhanced electrochemical performance. Adv. Funct. Mater. 2016, 26, 4760-4767.

(52) Liu, W.; Shi, Q.; Qu, Q.; Gao, T.; Zhu, G.; Shao, J.; Zheng, H., Improved Li-ion diffusion and stability of a $\mathrm{LiNi}_{0.5} \mathrm{Mn}_{1.5} \mathrm{O}_{4}$ cathode through in situ co-doping with dual-metal cations and incorporation of a superionic conductor. J. Mater. Chem. A 2017, $5,145-154$.

(53) Bai, Y.; Yan, D.; Yu, C.; Cao, L.; Wang, C.; Zhang, J.; Zhu, H.; Hu, Y.-S.; Dai, S.; Lu, J.; Zhang, W., Core-shell $\mathrm{Si} @ \mathrm{TiO}_{2}$ nanosphere anode by atomic layer deposition for Li-ion batteries. J. Power Sources 2016, 308, 75-82.

(54) Noor, N.; Chew, C. K. T.; Bhachu, D. S.; Waugh, M. R.; Carmalt, C. J.; Parkin, I. P., Influencing FTO thin film growth with thin seeding layers: a route to microstructural modification. J. Mater. Chem. C 2015, 3, 9359-9368.

(55) Zou, P.; Li, J.; Zhang, Y.; Liang, C.; Yang, C.; Fan, H. J., Magnetic-field-induced rapid synthesis of defect-enriched $\mathrm{Ni}-\mathrm{Co}$ nanowire membrane as highly efficient hydrogen evolution electrocatalyst. Nano Energy 2018, 51, 349-357.

(56) Qing, R. P.; Shi, J. L.; Xiao, D. D.; Zhang, X. D.; Yin, Y. X.; Zhai, Y. B.; Gu, L.; Guo, Y. G., Enhancing the kinetics of Li-rich cathode materials through the pinning effects of 
gradient surface $\mathrm{Na}^{+}$doping. Adv. Energy Mater. 2016, 6, 1501914.

(57) Hai, B.; Shukla, A. K.; Duncan, H.; Chen, G., The effect of particle surface facets on the kinetic properties of $\mathrm{LiNi}_{0.5} \mathrm{Mn}_{1.5} \mathrm{O}_{4}$ cathode materials. J. Mater. Chem. A 2013, 1 , 759-769.

(58) Shen, L.; Chen, S.; Maier, J.; Yu, Y., Carbon-coated $\mathrm{Li}_{3} \mathrm{VO}_{4}$ spheres as constituents of an advanced anode material for high-rate long-life lithium-ion batteries. Adv. Mater. 2017, 29, 1701571.

(59) Deng, Y. F.; Zhao, S. X.; Zhai, P. Y.; Cao, G.; Nan, C. W., Impact of lithium excess on the structural and electrochemical properties of the $\mathrm{LiNi}_{0.5} \mathrm{Mn}_{1.5} \mathrm{O}_{4}$ high-voltage cathode material. J. Mater. Chem. A 2015, 3, 20103-20107.

(60) Amin, R.; Belharouk, I., Part I: Electronic and ionic transport properties of the ordered and disordered $\mathrm{LiNi}_{0.5} \mathrm{Mn}_{1.5} \mathrm{O}_{4}$ spinel cathode. J. Power Sources 2017, 348, $311-317$

(61) Amin, R.; Belharouak, I., Part-II: Exchange current density and ionic diffusivity studies on the ordered and disordered spinel $\mathrm{LiNi}_{0.5} \mathrm{Mn}_{1.5} \mathrm{O}_{4}$ cathode. J.Power Sources 2017, 348, 318-325.

(62) Wen, H.; Zhang, J.; Chai, J.; Ma, J.; Yue, L.; Dong, T.; Zang, X.; Liu, Z.; Zhang, B.; Cui, G., Sustainable and superior heat-resistant alginate nonwoven separator of $\mathrm{LiNi}_{0.5} \mathrm{Mn}_{1.5} \mathrm{O}_{4} / \mathrm{Li}$ batteries operated at $55{ }^{\circ} \mathrm{C}$. ACS Appl. Mater. Interfaces 2017, 9, 
3694-3701.

(63) Ben, L. B.; Yu, H. L.; Wu, Y. D.; Chen, B.; Zhao, W. W.; Huang, X. J., Ta2 $\mathrm{O}_{5}$ coating as an HF barrier for improving the electrochemical cycling performance of high-voltage spinel $\mathrm{LiNi}_{0.5} \mathrm{Mn}_{1.5} \mathrm{O}_{4}$ at elevated temperatures. ACS Appl. Energy Mater. 2018, 1, 5589-5598.

(64) Liu, S.; Liu, Z.; Shen, X.; Li, W.; Gao, Y.; Banis, M. N.; Li, M.; Chen, K.; Zhu, L.; Yu, R.; Wang, Z.; Sun, X.; Lu, G.; Kong, Q.; Bai, X.; Chen, L., Surface doping to enhance structural integrity and performance of Li-rich layered oxide. Adv. Energy Mater. 2018, 8,1802105 .

(65) Wu, H. M.; Belharouak, I.; Abouimrane, A.; Sun, Y. K.; Amine, K., Surface modification of $\mathrm{LiNi}_{0.5} \mathrm{Mn}_{1.5} \mathrm{O}_{4}$ by $\mathrm{ZrP}_{2} \mathrm{O}_{7}$ and $\mathrm{ZrO}_{2}$ for lithium-ion batteries. J. Power Sources 2010, 195, 2909-2913.

(66) Song, B.; Li, W.; Oh, S. M.; Manthiram, A., Long-life Nickel-rich layered oxide cathodes with a uniform $\mathrm{Li}_{2} \mathrm{ZrO}_{3}$ surface coating for lithium-ion batteries. ACS Appl. Mater. Interfaces 2017, 9, 9718-9725. 
Table 1. EIS Fitting data of the pristine and $1 \mathrm{wt} . \%$ LVPO-LNMO samples.

\begin{tabular}{|c|c|c|c|c|}
\hline Resistance & Electrode & $1^{\mathrm{st}}$ & $30^{\text {th }}$ & $60^{\text {th }}$ \\
\hline \multirow[b]{2}{*}{$\mathrm{R}_{\mathrm{sf}}(\Omega)$} & Pristine & 199.4 & 903.9 & 1527.4 \\
\hline & $\begin{array}{c}1 \text { wt. } \% \\
\text { LVPO-LNMO }\end{array}$ & 145.6 & 157.8 & 289.5 \\
\hline \multirow[b]{2}{*}{$\mathrm{R}_{\mathrm{ct}}(\Omega)$} & Pristine & 320.1 & 1364.4 & 2133.9 \\
\hline & $\begin{array}{c}1 \text { wt. } \% \\
\text { LVPO-LNMO }\end{array}$ & 162.8 & 181.5 & 345.9 \\
\hline
\end{tabular}




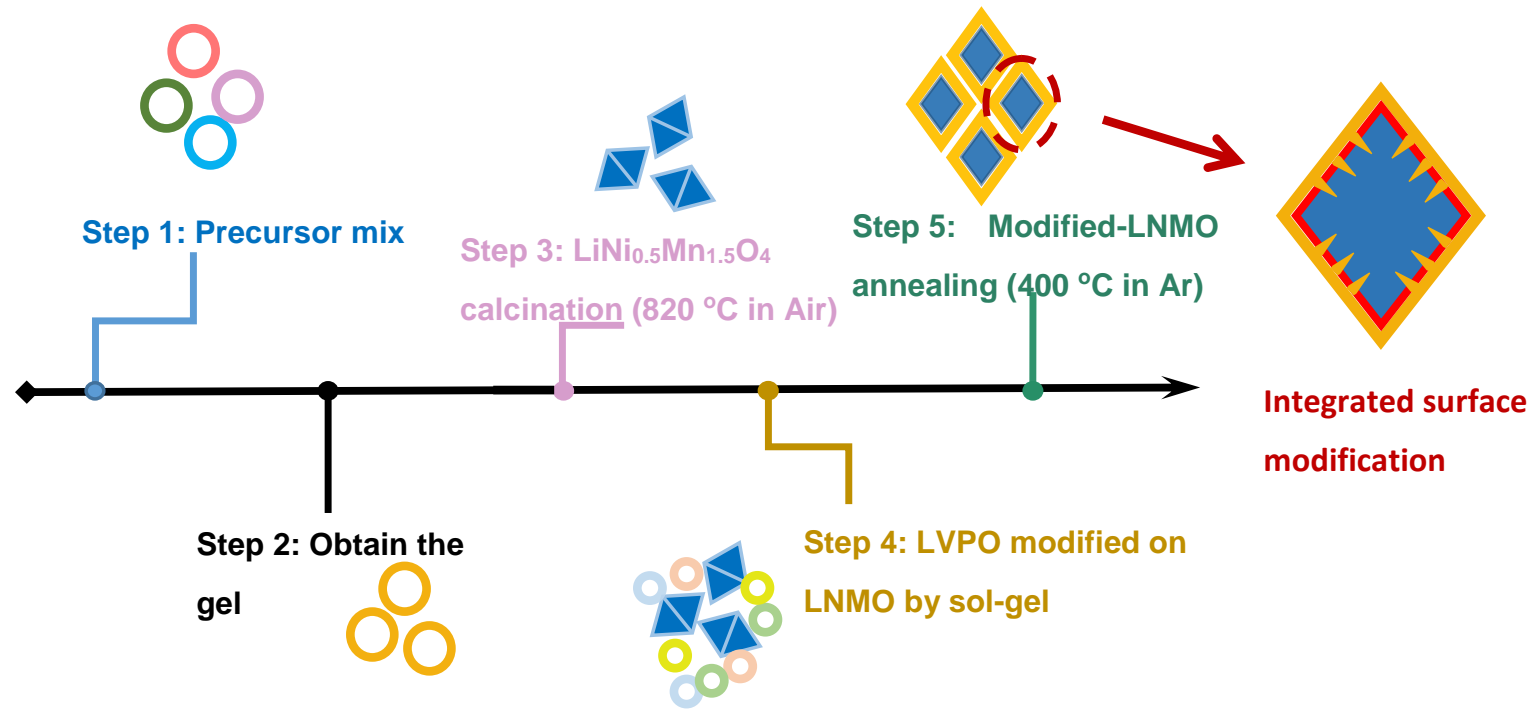

Scheme 1. Schematic diagram for synthesis of the pristine $\mathrm{LiNi}_{0.5} \mathrm{Mn}_{1.5} \mathrm{O}_{4}(\mathrm{LNMO})$ and the $\mathrm{Li}_{3} \mathrm{~V}_{2}\left(\mathrm{PO}_{4}\right)_{3}$-modified $\mathrm{LiNi}_{0.5} \mathrm{Mn}_{1.5} \mathrm{O}_{4}$ (LVPO-LNMO) materials. 


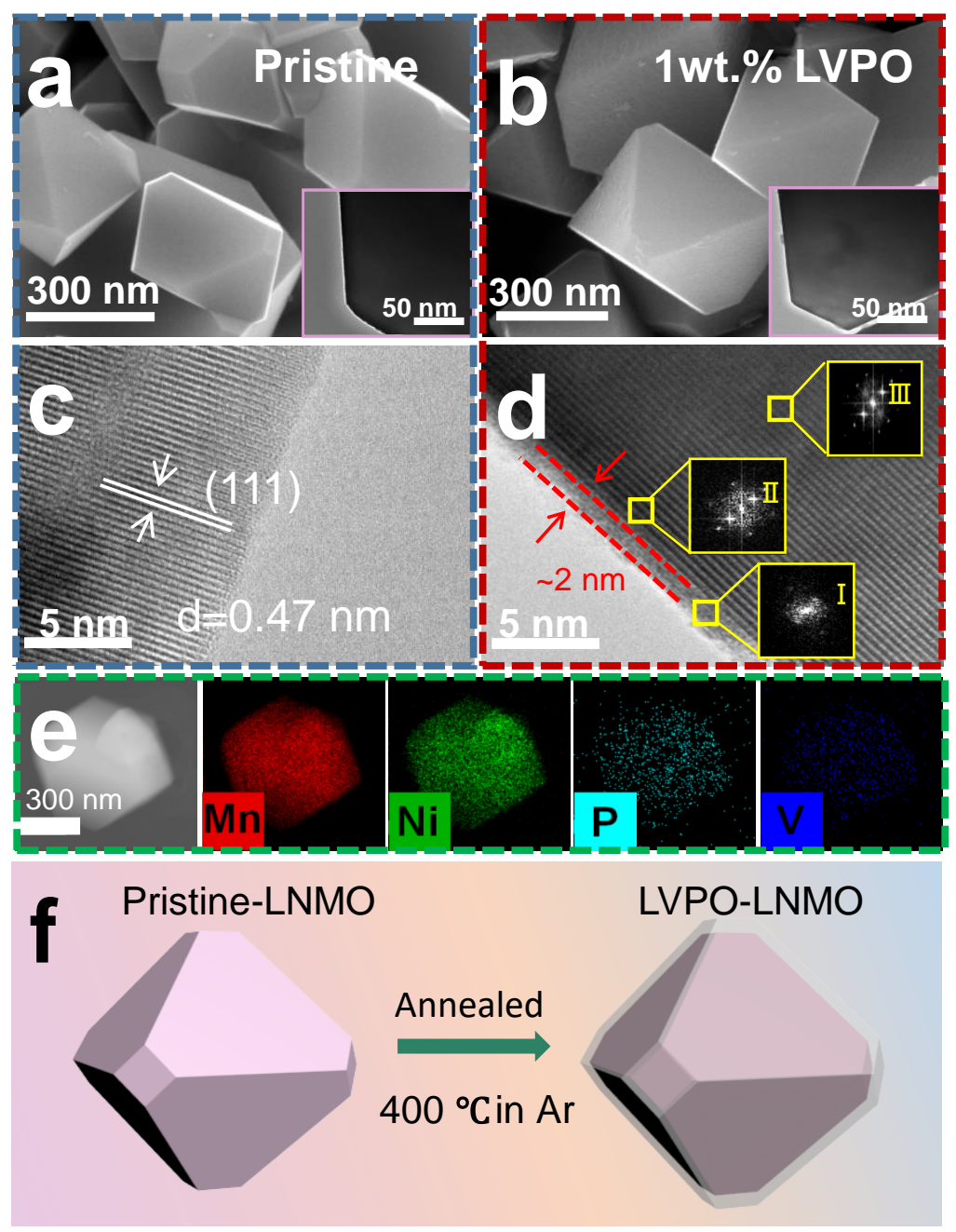

Figure 1. SEM images of the pristine and the 1 wt.\% LVPO-LNMO samples (a-b), and their HRTEM images with the inserted SAED images (c-d). The typical EDS mappings for the elements of $\mathrm{Mn}, \mathrm{Ni}, \mathrm{P}$ and $\mathrm{V}$ consisted in one particle of the $1 \mathrm{wt}$.\% LVPO-LNMO sample (e). The morphology schematic diagram of pristine and the LVPO-LNMO samples (f). 

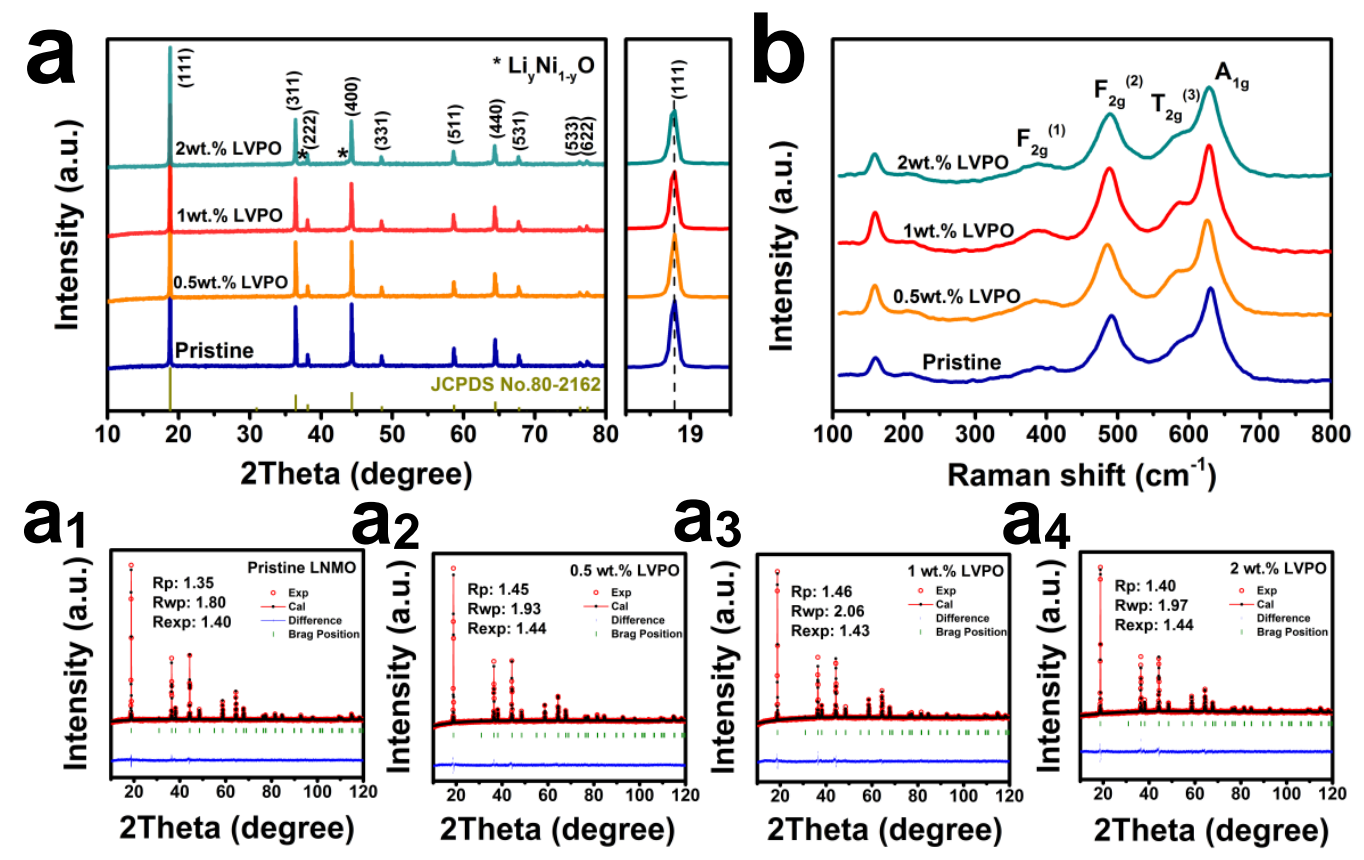

Figure 2. XRD patterns of the pristine and the LVPO-LNMO samples (a), and their corresponding Rietveld refinement spectra $\left(\mathrm{a}_{1}-\mathrm{a}_{4}\right)$. Raman spectra of all four samples in the wavenumber range from 100 to $800 \mathrm{~cm}^{-1}$ (b). 


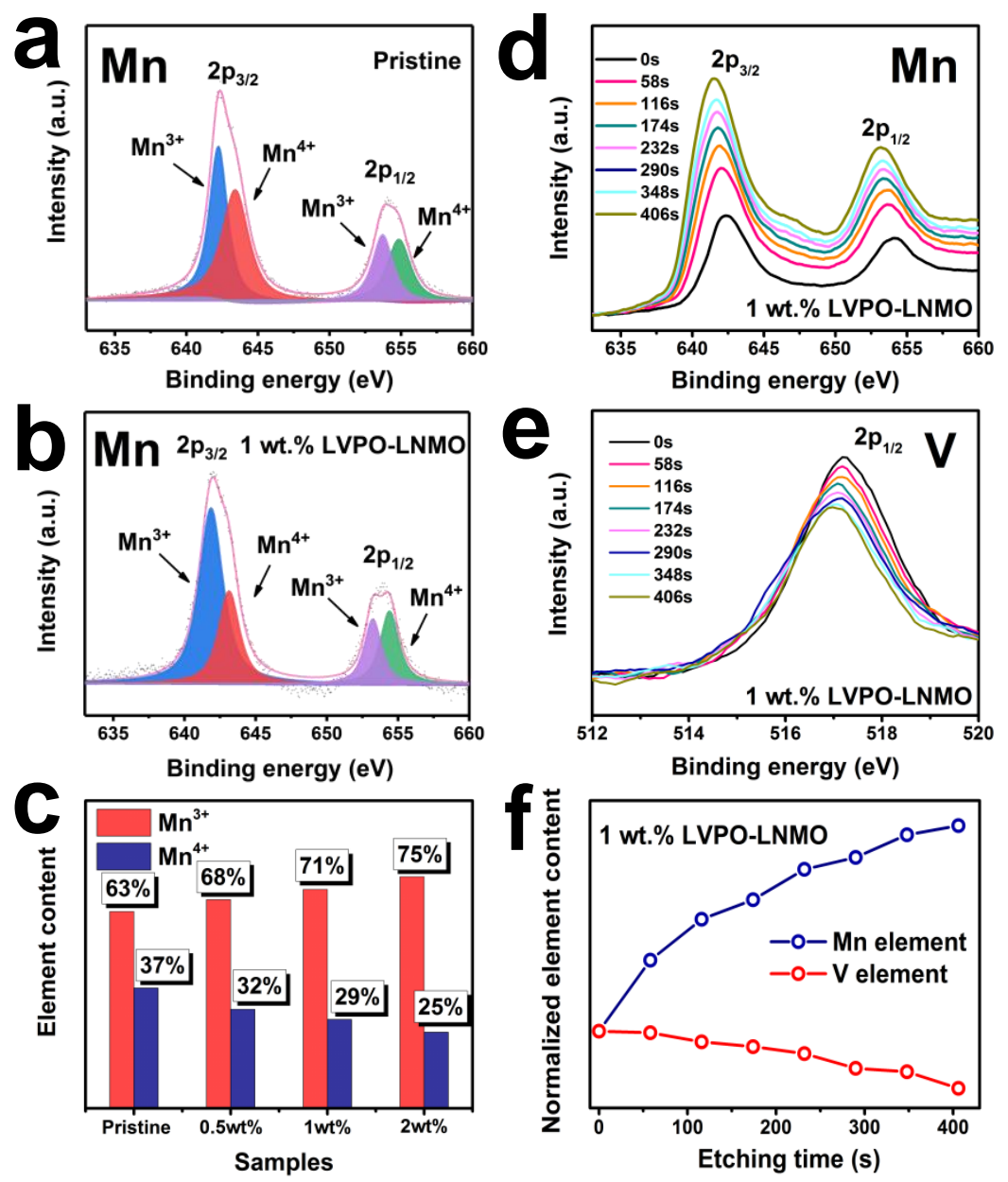

Figure 3. Mn 2p XPS spectra for the pristine and the 1 wt.\% LVPO-modified LNMO samples (a-b). Relative percentages of $\mathrm{Mn}^{3+}$ and $\mathrm{Mn}^{4+}$ in the $\mathrm{Mn} 2 \mathrm{p}_{3 / 2}$ region (c). The XPS sputtered depth profiles of the Mn $2 p$ and the V $2 p$ in the 1 wt.\% LVPO-LNMO sample (d-e), and the change curves of these two element contents along with etching time(f). 

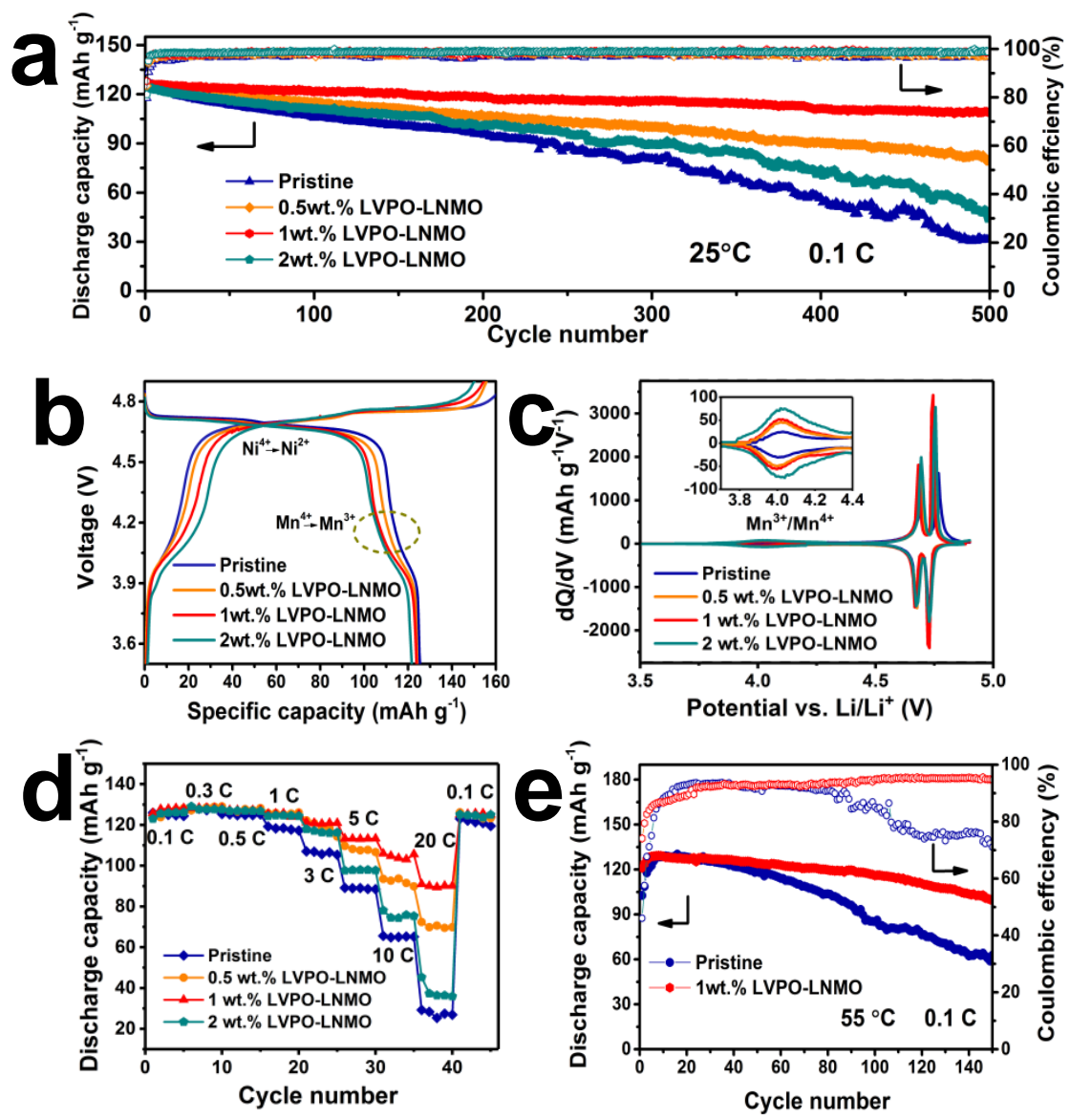

Figure 4. Cycling life, charge-discharge profiles at $1^{\text {st }}, \mathrm{dQ} / \mathrm{dV}$ curves and rate capability of the all samples at $25{ }^{\circ} \mathrm{C}\left(0.1 \mathrm{C}, 14.7 \mathrm{mAh} \mathrm{g}^{-1}\right)$ (a-d). Cycling performances of the pristine and the 1 wt.\% LVPO-LNMO samples at a high temperature of $55^{\circ} \mathrm{C}(0.1 \mathrm{C}$, 14.7 $\left.\mathrm{mAh} \mathrm{g}^{-1}\right)(\mathrm{e})$. 

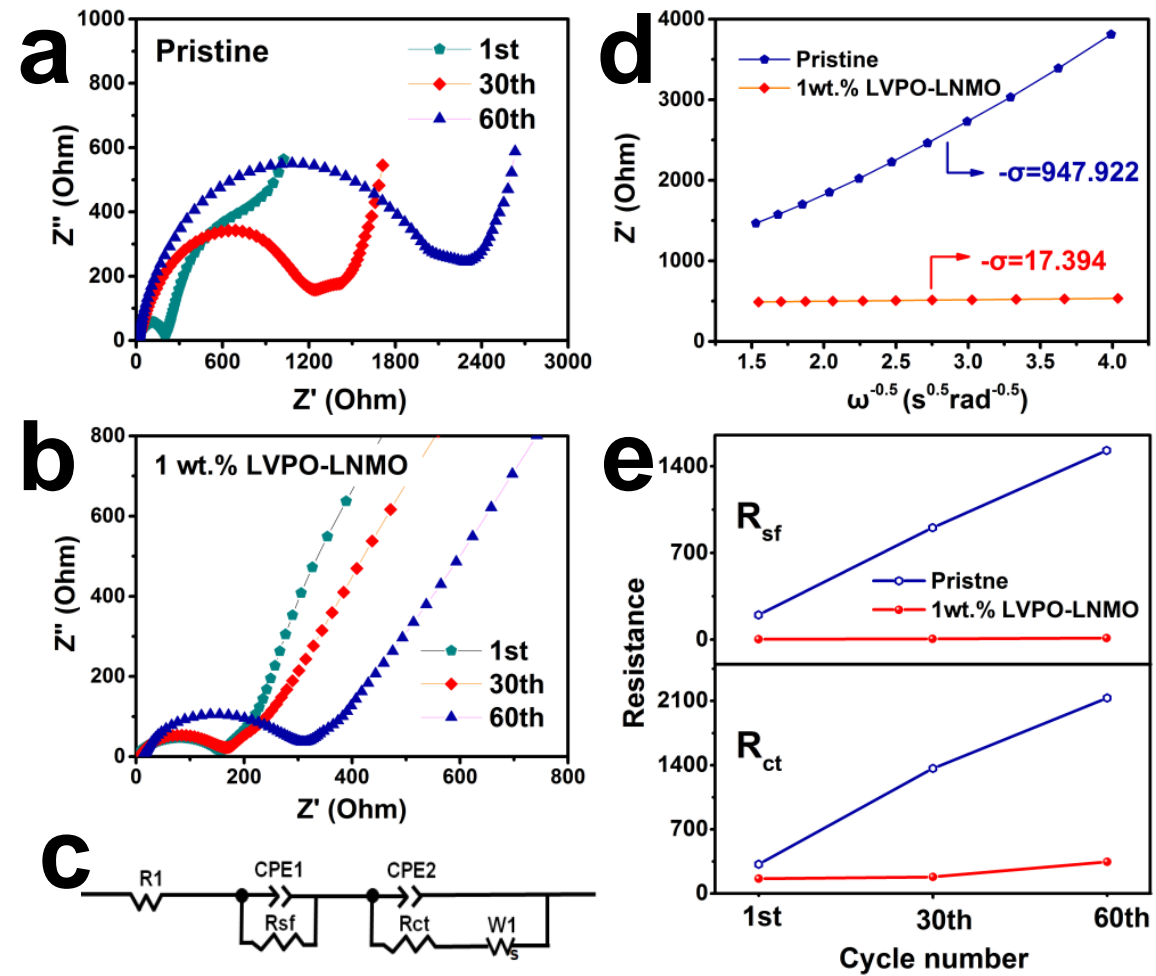

Figure 5. Nyquist plots of the pristine and $1 \mathrm{wt} . \%$ LVPO-LNMO after different cycles (a-b) and equivalent circuit (c). $Z_{\text {re }}$ vs. $\omega^{-0.5}$ plots in the low-frequency region obtained from EIS measurements of two samples (d). Evolution of the normalized surface resistance $\mathrm{R}_{\mathrm{sf}}$ and charge transfer resistance $\mathrm{R}_{\mathrm{ct}}(\mathrm{e})$. 


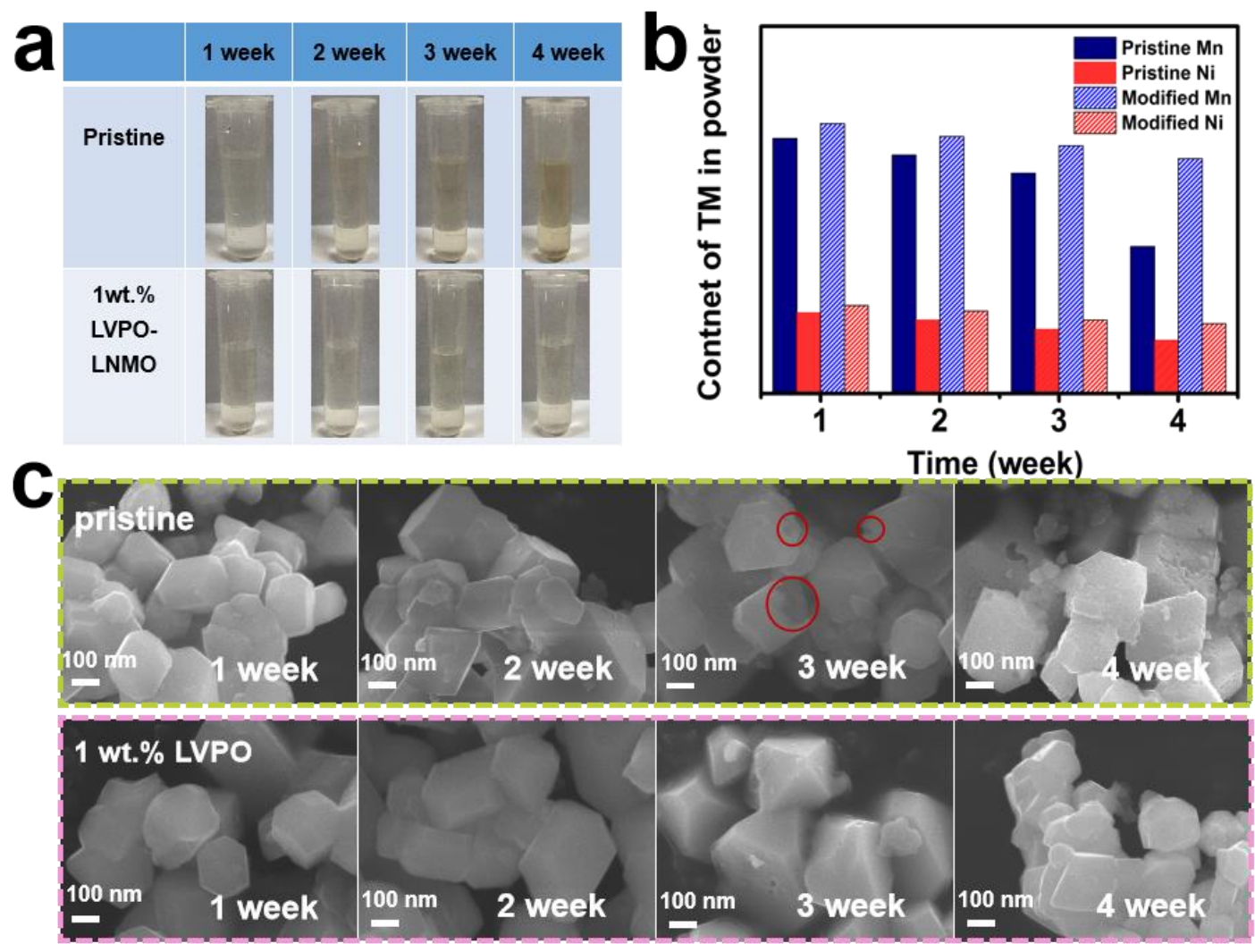

Figure 6. Photos for the color change of the electrolytes with different soakage time (a), the histogram for the ICP data (b). SEM images of the pristine and $1 \mathrm{wt} \%$ LVPO-LNMO samples after different soakage weeks. 


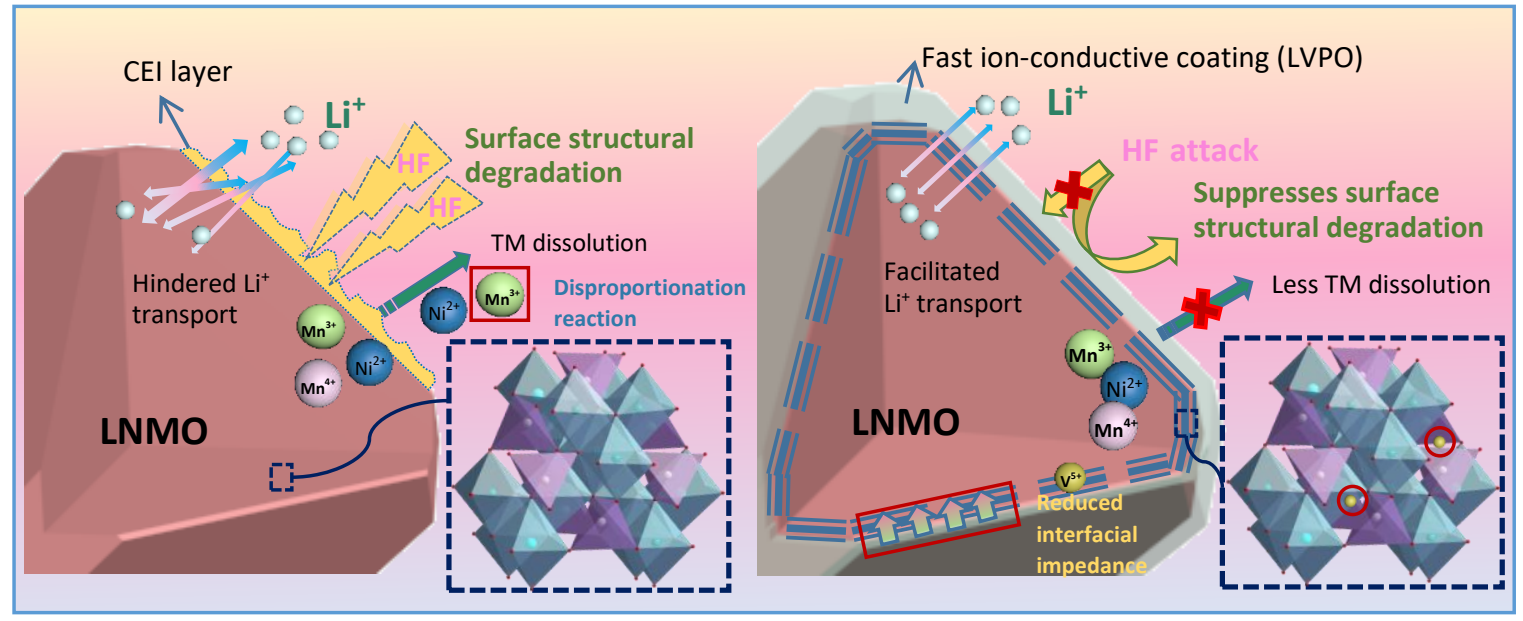

Scheme 2. Schematic of the advantages of integrated surface modification to stabilize the surface of the LNMO particle. 


\section{Research Highlights}

- The design and construction of one-step integrated surface modification is proposed.

- Fast ion conductor surface coating to structure stability through suppressing $\mathrm{R}_{\text {sf }}$ growth.

- Surface gradient doping is significant for the interfacial compatibility via alleviating $\mathrm{R}_{\mathrm{ct}}$. 


\section{Table of Contents}

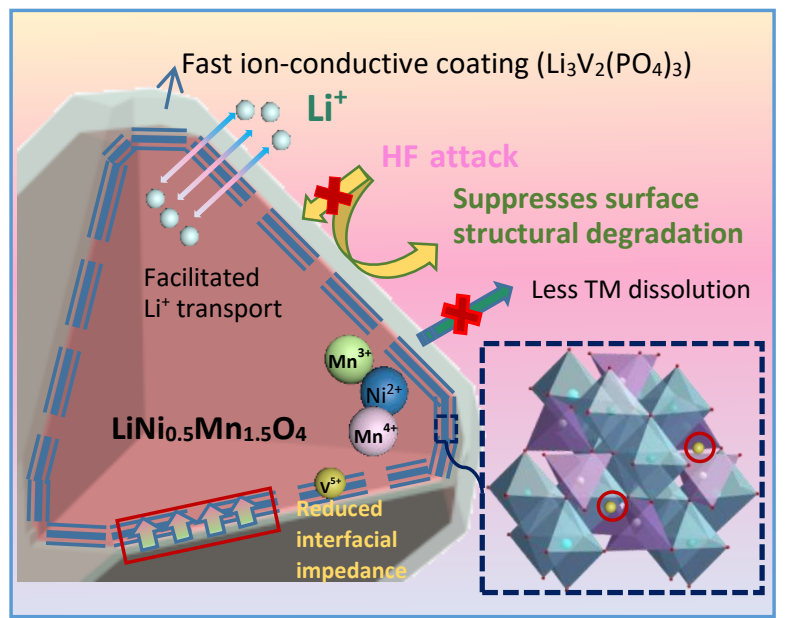

The integrated strategy of LVPO surface modification proposed in this work, combing the benefits of surface coating (to stabilize the material surface) and surface doping (to improve the interface compatibility), proves to be an effective approach to comprehensively enhance the utilizability of LNMO towards high energy density area. Therefore, the one-step integrated surface modification proposed herein not only paves 
the way to more convenient modification strategy for electrode construction with better properties for secondary batteries, including $\mathrm{Li}^{+}, \mathrm{Na}^{+}, \mathrm{K}^{+}, \mathrm{Mg}^{2+}, \mathrm{Al}^{3+}, \mathrm{Li}-\mathrm{S}$ and $\mathrm{Li}-\mathrm{O}$ batteries, but also sheds light in more in-depth mechanism exploration and broad application in a wide range of electrochemical systems as well as the community of surface/interface decorations. 